\title{
ANÁLISE DO NÍVEL DE SATISFAÇÃO DOS CLIENTES DE UMA EMPRESA DE PEQUENO PORTE
}

\section{ANALYSIS OF CUSTOMERS SATISFACTION LEVEL FROM A SMALL COMPANY}

\author{
Isabella Botelho Pavoni ${ }^{1}$ \\ André Luís Janzkovski Cardoso ${ }^{2}$
}

\begin{abstract}
Resumo
O objetivo do estudo foi analisar o nível de satisfação de clientes de uma pequena empresa do setor de estética, localizada na cidade de Rondonópolis (MT), a partir dos aspectos demográficos. Abordagens quantitativas e qualitativas foram utilizadas, apoiadas pelo método SERVPERF. Os dados foram coletados por meio de questionários físicos e eletrônicos, e foram analisados por meio do software Statistical Package of Social Sciences, aplicando-se estatística bivariada, análise fatorial, teste de confiabilidade, análise de correlação e comparativo entre médias. Com base na análise fatorial, as respostas foram agrupadas em quatro fatores que foram testados, considerando os aspectos demográficos dos clientes. Os resultados indicam que os dados estavam significativamente correlacionados e que o método SERVPERF foi adequado para o processamento e análise dos dados. Das seis hipóteses formuladas inicialmente, três foram corroboradas. Os dados qualitativos também foram utilizados para complementar a análise quantitativa, evidenciando os achados e apontando para diferentes percepções de clientes.
\end{abstract}

Palavras-chave: qualidade de serviços. método SERVPERF. nível de satisfação.

\begin{abstract}
The objective of the study was to analyze customer's satisfaction level from a small company in the aesthetics sector, located in the city of Rondonópolis-MT, based on demographic aspects. Quantitative and qualitative approaches were used, supported by the SERVPERF method. The data was collected using physical and electronic questionnaires, and the data were analyzed through the Statistical Package of Social Sciences software, applying bivariate statistics, factorial analysis, reliability test, correlation analysis, and comparative between averages. Based on the factorial analysis, the answers were grouped into four factors that were tested, considering the customers' demographic aspects. The results indicate that the data were significantly correlated and that the SERVPERF method was suitable for data processing and analyzes. Of the six hypotheses initially proposed, three were corroborated. The qualitative data also was used to complement the quantitative analysis, evidencing the findings, and pointing to different perceptions of customers.
\end{abstract}

Key-words: quality of services. SERVPERF method. satisfaction level.

\footnotetext{
${ }^{1}$ Universidade Federal de Rondonópolis. E-mail: isabella_pavoni@ hotmail.com

2 Professor Dr. André Luís Janzkovski Cardoso, PMP Universidade Federal de Rondonópolis. E-mail:

cardoso9778@gmail.com
}

Artigo recebido em: 09 de janeiro de 2019. Artigo aceito em 25 de junho de 2019 . 


\section{PAVONI; CARDOSO}

\section{Introdução}

Com o aumento da competitividade, as empresas precisam ter desempenho e excelência na prestação de serviços para conquistar e manter os clientes. Isto pode acontecer por meio do oferecimento de serviços com qualidade, atendimento de excelência, capacidade e habilidade de suprir a demanda e corresponder às expectativas de seus clientes. Neste contexto, conhecer os clientes e seus anseios é a melhor maneira de a empresa atender tais expectativas.

Alguns estudos foram realizados sobre a satisfação dos clientes acerca de serviços oferecidos por estabelecimentos no segmento da beleza. Esses estudos relacionam a satisfação dos clientes, a qualidade do serviço prestado, envolvendo afeição e emoção na execução, além de fatores como valor ou preço (GOUVÊA; MASANO; MANTOVANI, 2017).

Segundo Magaldi e Crescitelli (2008), o grau de satisfação dos clientes com a empresa é decorrência de um estudo comparativo com relação à expectativa que se tem dos serviços contratados e a visão que o cliente passa a ter após a prestação do serviço. Por isso, é importante ter um conhecimento prévio do que o cliente busca na empresa e chegar mais perto das suas expectativas (AQUINO; JERÔNIMO; MELO, 2015).

Desta forma, este estudo se mostra relevante, pois busca-se responder ao seguinte problema de pesquisa: Qual é o nível de satisfação dos clientes em relação à prestação de serviços da empresa Beleza e Arte a partir de aspectos demográficos? Para responder a esse problema, estabeleceu-se o objetivo geral de analisar o nível de satisfação dos clientes de uma empresa de pequeno porte atuante no ramo da estética na cidade de Rondonópolis (MT), a partir dos aspectos demográficos. Com isso, os objetivos específicos deste trabalho foram: (1) identificar o perfil demográfico dos clientes; (2) agrupá-los em classes; (3) identificar o nível de satisfação dos clientes com relação aos serviços oferecidos considerando os aspectos demográficos.

Para tanto, utilizou-se o método SERVPERF pela facilidade de aplicação e compreensão, sendo possível apresentar de forma clara a opinião dos clientes com relação à qualidade dos serviços prestados. Tal método relaciona a visão dos clientes sobre a qualidade dos serviços prestados pela empresa com base em cinco dimensões, quais sejam: (1) confiabilidade, (2) sensibilidade ou presteza, (3) segurança, (4) empatia e (5) tangibilidade.

Busca-se com este estudo contribuir de forma teórica e metodológica à medida que pode

Revista Eletrônica Gestão e Serviços v.10, n. 1, pp. 2703 - 2730, Janeiro/Junho 2019.

ISSN Online: 2177-7284 e-mail: regs@ metodista.br 


\section{PAVONI; CARDOSO}

reforçar a aplicabilidade da ferramenta na identificação de aspectos indicados pela teoria em um modelo adaptado ao perfil de pequena empresa no ramo da estética. Entende-se haver uma contribuição prática tendo em vista que o estudo traz informações a respeito do nível de satisfação dos clientes com relação à qualidade dos serviços prestados pela empresa pesquisada.

Este estudo está dividido em cinco seções, considerando esta apresentação inicial. A seguir, apresenta-se o referencial teórico, os procedimentos metodológicos, a análise dos dados e discussão dos resultados e, por fim, as considerações finais.

\section{REFERENCIAL TEÓRICO}

O referencial deste artigo apresenta questões envolvendo satisfação de clientes, qualidade de serviços e modelos para mensurar o nível de satisfação.

\section{SATISFAÇÃO DE CLIENTES}

Com o mercado cada vez mais competitivo, as empresas estão preocupadas com a satisfação de seus clientes que, por sua vez, estão cada vez mais exigentes. Para tanto, há diversas definições para o termo satisfação do cliente, que vai além da busca apenas por produto de qualidade, pois se tem exigido atendimento de excelência e uma prestação de serviços eficiente.

Segundo Kotler (2000), a satisfação de clientes é função de desempenho e expectativas percebidas, ou seja, a satisfação consiste na sensação do prazer ou desapontamento, advindo da comparação do resultado percebido de um serviço em relação às expectativas formuladas, inicialmente, pelo cliente. Da mesma forma, para Juran (1997), a satisfação do cliente está relacionada ao resultado esperado pelo consumidor após a entrega do produto ou serviço prestado e se o mesmo, após finalizado, atendeu suas expectativas.

Deste modo, a satisfação pode ser entendida como a diferença entre a expectativa do cliente e sua percepção sobre o serviço oferecido. Para que a satisfação seja alcançada, é necessário compreender as necessidades e as expectativas do consumidor e, posteriormente, traduzi-las em requisitos, bem como cumpri-los (BOAS et al., 2003). Em outras palavras, quando as expectativas do cliente são atendidas ou superadas, há maior probabilidade de recompra de produtos ou serviços utilizados. Ao contrário, caso suas expectativas não sejam atendidas, o cliente ficará insatisfeito, gerando uma visão 


\section{PAVONI; CARDOSO}

negativa da empresa e reduzindo a possibilidade de recompra.

Neste caso, a parte psicológica do cliente é a responsável por definir se está ou não satisfeito e quais características podem ser atreladas ao produto ou serviço em termos de sentimento, expressividade e divulgação. A satisfação seria uma reação daquilo que foi utilizado, de maneira que um cliente insatisfeito divulga, em média, para outras nove pessoas sua experiência negativa (TARP, 1986 apud FERNANDES; SANTOS, 2008, p. 153). Já segundo Bateson e Hoffman (2001), um em cada dezenove clientes expressam seu sentimento de insatisfação para a empresa por meio de reclamações formais ou informais, dando a oportunidade de a empresa tratar o problema. Quando esse problema é resolvido de forma satisfatória, aquele cliente que anteriormente estava insatisfeito tende a espalhar essa notícia a cinco outras pessoas a respeito do resultado bemsucedido.

Na visão de Gastal (2005, p. 27),

Os consumidores mostram-se satisfeitos quando o resultado excede às expectativas (desconfirmação positiva), ou não se mostram satisfeitos quando as expectativas são maiores que o resultado (desconfirmação negativa), ou, ainda, mostram-se simplesmente satisfeitos quando o resultado apenas coincide com as expectativas (não há desconfirmação).

Anderson, Fornell e Lehmann (1994 apud GASTAL, 2005) apresentam o conceito de satisfação do cliente baseado em duas esferas: satisfação específica e cumulativa. A satisfação específica da transação se dá, principalmente, com a relação entre consumidor e produto, como um julgamento após uma escolha específica de transação, ou seja, uma compra. Já a satisfação cumulativa acontece com as transações gerais da empresa com o cliente, e é definida como um julgamento baseado em experiências totais de compra e seu consumo durante o tempo.

Assim, conforme Beulke (1998), a satisfação do cliente pode ser definida como o nível de sentimento do consumidor, responsável pelo resultado do consumo de um produto ou serviço em relação a suas expectativas ou o desempenho do mesmo.

A satisfação do cliente está ligada à ambiguidade de sentimento decorrente de várias experiências, sejam elas positivas ou negativas em relação à aquisição de um produto ou serviço. Essa experiência é progressiva, pode ser influenciada por diversos acontecimentos e passar por uma evolução. Sempre que o cliente passa por uma experiência ao adquirir um produto ou serviço, seu entendimento com respeito à 


\section{PAVONI; CARDOSO}

satisfação pode ser alterado.

Desta forma, mensurar o nível da satisfação é uma maneira de adequar a prestação de serviços às necessidades do consumidor, com a intenção de proporcionar uma visão mais próxima à realidade daquela que a organização vivencia. Oferecer ao cliente mais do que ele espera é superar sua expectativa e com isso contribuir para o desenvolvimento da sua satisfação, fidelização e, consequentemente, na realização de processos de recompra. Na percepção de Patterson (1993 apud FARIAS; SANTOS, 2000, p. 125), “[...] a satisfação do consumidor é um fenômeno pós-compra; assim, reflete o quanto o consumidor gosta ou não gosta de um produto, após o uso".

Helena e Spers (2005) destacam que, para que seja feita uma avaliação referente ao nível de satisfação do consumidor, é importante levar em consideração o que o cliente espera com relação ao produto ou serviço utilizado. Avaliar a satisfação é uma atitude preventiva que a empresa deve realizar. Como benefício para a organização, avaliar constantemente a satisfação dos clientes é uma forma de realimentar e controlar os esforços para gerar valor do ponto de vista dos seus clientes (MARCHETTI; PRADO, 2001).

Como desafio, as empresas buscam aumentar a oferta de serviços de qualidade com o objetivo de se manter ou se diferenciar no mercado competitivo, garantindo a satisfação do consumidor. O próximo tópico explora as questões da qualidade de serviços.

\section{QUALIDADE DE SERVIÇOS}

Santos e Fernandes (2008) afirmam que a confiança do consumidor no contexto de serviços tem sido estudada como um conceito bidimensional, em que uma dimensão diz respeito à confiança nos funcionários da linha de frente e a outra se relaciona às políticas da empresa prestadora de serviços. A confiança, a satisfação e o valor percebido influenciam tanto a intenção de recompra como na comunicação boca-a-boca. A forma como o produto ou serviço é oferecido ou apresentado e a qualidade na entrega do resultado esperado contará como fator determinante para que o consumidor se sinta satisfeito e confiante para repassar seu sentimento de satisfação a outros clientes. Todos os fatores abrangentes, desde o atendimento inicial até a entrega do produto ou serviço final, são considerados importantes na visão do cliente. Segundo Magaldi e Crescitelli (2008), a formação geral da satisfação de um consumidor é resultado de sua interação com todos os processos relacionados ao serviço de qualidade prestado e não somente

Revista Eletrônica Gestão e Serviços v.10, n. 1, pp. 2703 - 2730, Janeiro/Junho 2019. ISSN Online: 2177-7284 e-mail: regs@metodista.br 


\title{
PAVONI; CARDOSO
}

com aqueles relacionados exclusivamente ao serviço essencial. Esse comportamento apresentado pelos clientes é uma consequência da relação desenvolvida com os processos que abrangem toda a prestação de um serviço de forma geral e não em relação aos fatores de forma separada (MAGALDI; CRESCITELLI, 2008).

Partindo dessa premissa, o cliente tem a experiência com os fatores durante as etapas do atendimento até que o processo chegue ao fim. Assim, caso um erro aconteça em uma das etapas, tudo o que foi feito de forma correta até aquele momento perde a importância e o serviço é visto de forma negativa. O tratamento que o cliente recebe da empresa é o primeiro impacto que o leva a continuar ou não consumindo produtos e serviços dessa empresa.

A qualidade na prestação de serviços é de extrema importância para a organização que busca se destacar no mercado, por meio de estratégias bem definidas. Preza-se pela qualidade na prestação de serviço a fim de reduzir desperdícios, reduzir as margens de erros, tratando qualquer tipo de insatisfação dos clientes, deste modo, possibilitando que o cliente crie um laço de confiança com a organização e realize processos de recompra. Fornell (1992 apud GASTAL, 2005, p. 24), afirma que,

\begin{abstract}
Para as organizações, entre os inúmeros benefícios recebidos por nutrir clientes altamente satisfeitos estão a menor elasticidade de preços, distanciamentos dos clientes de ofertas da concorrência, menores custos de transações futuras, custos de falha reduzidos, menor custo para atrair novos clientes, além da melhora da reputação da empresa e, por conseguinte, maior lealdade dos clientes.
\end{abstract}

O uso da política de gestão da qualidade em uma organização tem como objetivo direcionar os esforços de todos as partes interessadas para o bom andamento da mesma. As partes interessadas de uma organização envolvem: clientes, fornecedores, sócios, funcionários e comunidade. O critério verdadeiramente importante com relação à qualidade oferecida é a visão que o cliente teve do produto ou serviço e se suas expectativas foram atendidas.

Gianesi e Corrêa (1994) acreditam que a qualidade dos serviços pode ser avaliada no momento em que os serviços ficam visíveis ao consumidor, e a satisfação do cliente pode ser mensurada ao término do serviço em que indicar se está satisfeito ou surpreendido com o que recebeu, ou, ao contrário, demonstrar sua insatisfação. Para Rodrigues (2000), a gestão da qualidade deve estar preparada para superar as expectativas do cliente e satisfazê-lo em todas as transações com a empresa. Ademais, 


\section{PAVONI; CARDOSO}

Santos e Fernandes (2008, p. 13) indicam que, "[...] quando o consumidor percebe a performance da empresa como justa e satisfatória, seus sentimentos de confiança tendem a ser reforçados”. Para os autores, a relação entre satisfação e confiança parece potencializar a relação da empresa com o consumidor, especialmente no tocante aos serviços prestados, levando a um sentimento de valorização e de que a empresa investe na manutenção de seus clientes.

Reforçando este argumento, na visão de Zeithaml e Bitner (2003), a qualidade do serviço é influenciada pelo que se espera do mesmo e de como será percebido por quem o recebe. A empresa tem que ser capaz de melhorar a qualidade dos serviços, a fim de atender às necessidades e aos desejos de seus clientes. Por isso, Farias e Santos (2000) afirmam que é preciso estar preparado e capaz de desenvolver uma ampla variedade de produtos e serviços de qualidade para oferecer e se manter competitivo no mercado.

Segundo Rossi e Slongo (1998), a pesquisa de satisfação é um conjunto de informações sobre a opinião dos clientes com relação à satisfação com os serviços prestados pela empresa, possibilitando mensurar a qualidade dos serviços oferecidos e adotar estratégias de melhorias aumentando sua competitividade. Para os autores, são inúmeras as vantagens da realização de uma avaliação do nível de satisfação dos clientes, como levantar informações sobre necessidades dos clientes, possibilidade de identificar problemas por meio de feedbacks, desenvolver uma relação de confiança e lealdade entre o cliente e a empresa, e até mesmo melhorar a imagem da empresa a partir de ações desencadeadas como resultado da pesquisa de satisfação.

A mensuração da qualidade dos serviços e o nível de satisfação dos clientes podem ter consequências favoráveis à empresa, pois o desempenho dos serviços pode ser uma fonte de vantagem competitiva e o nível de satisfação pode indicar melhorias necessárias para aumentar a percepção de valor por parte dos clientes.

Em um estudo bibliométrico, com publicações internacionais, os autores Almeida, Carneiro e Pelissari (2017) investigaram as principais consequências da qualidade do serviço (QS) entre 1980 e 2016. Os resultados indicam que, dos 95 artigos analisados, os principais consequentes da QS são a satisfação, a lealdade, a intenção de comportamento do consumidor e o desempenho financeiro da organização. Desta forma, reforça-se a importância de mensurar a satisfação dos clientes, especialmente com a qualidade dos serviços.

Há vários modelos e métodos para que seja possível realizar uma avaliação do nível de 
satisfação dos clientes com relação aos serviços prestados pela empresa; alguns deles são apresentados no tópico a seguir.

\section{MODELOS PARA ANALISAR O NÍVEL DE SATISFAÇÃO DOS CLIENTES}

O modelo ACSI (American Customer Satisfaction Index) é definido como um critério relacionado à economia, que define um ambiente passível de interpretação da opinião com relação aos preços executados e às mudanças propostas. $\mathrm{O}$ modelo tem por finalidade auxiliar no entendimento sobre as características relacionadas ao produto oferecido por meio da percepção do cliente (SILVA; GONÇALVES, 2007). É possível, a partir desse modelo de avaliação, definir o nível de qualidade que interessa ao cliente, relacionar a satisfação do cliente com a experiência que ele teve em outras empresas, perceber a satisfação do cliente de acordo com o valor oferecido nas mercadorias e equilibrar o resultado da satisfação do cliente com o resultado da aplicação do modelo ACSI (GASTAL, 2005). Este tipo de avaliação permite relacionar a empresa com seus concorrentes no mercado.

Outro método é o QFD (Quality Function Deployment) que demonstra o desejo dos clientes com relação aos serviços oferecidos, objetivando alcançar suas expectativas. Para que a empresa possa tentar alcançar tal objetivo, o cliente deve descrever suas necessidades, o tipo e a forma do produto ou da prestação de serviço (AKAO, 1990 apud MELO; JERÔNIMO; AQUINO, 2016).

O método AHP (Analitc Hierarchy Process), desenvolvido por Saaty, em 1980, foi criado com a finalidade de resolver possíveis problemas para a tomada de decisões, tanto de forma individual quanto em grupo, oferecendo uma melhor qualidade de acordo com a visão do cliente (SAATY, 1980 apud MELO; JERÔNIMO; AQUINO, 2016).

O método Kaiser faz uma análise agrupando as opiniões comuns dos clientes fazendo uso de técnicas estatísticas e que tem o objetivo de fazer a verificação das empresas concorrentes que apresentam diferenças com relação a características individuais da clientela e que possibilitem alcançar o resultado dos objetivos propostos pela empresa que aplica o modelo (ALVES et al., 2016).

As empresas que têm como principal preocupação a satisfação dos clientes podem fazer uso da logística reversa como um diferencial em relação aos concorrentes, reunindo valor do produto e satisfação em programas de relacionamento com clientes 


\section{PAVONI; CARDOSO}

(DAUGHERTY et al., 2001 apud GIACOBO; ESTRADA; CERETTA, 2003).

O BPAC (Balanço da Perspectiva Abrangente dos Clientes) também é um modelo de avaliação utilizando enquetes que são realizadas uma vez por ano fazendo comparações com enquetes de anos anteriores, a fim de saber se houve ou não melhora do atendimento e com isso mensurar a satisfação dos clientes com relação à empresa (FREIRE; CRISÓSTOMO; BOTELHO, 2003).

A diferença existente entre a expectativa do cliente e o desempenho da empresa é definida como GAP, outro método de avaliação, capaz de mensurar a qualidade do serviço oferecido. Segundo Xavier (2010), há cinco GAP's capazes de mensurar a qualidade do serviço: (1) discrepância entre o que o cliente quer (expectativas) e o que a gerência imagina serem aquelas expectativas; (2) discrepância entre a percepção por parte do gerente das expectativas do cliente e as especificações do serviço; (3) discrepância entre a especificação do serviço e o serviço prestado; (4) discrepância entre o serviço prometido (muito influenciado pelas comunicações externas) e o serviço prestado; e (5) afastamento entre as expectativas do cliente antes de receber um serviço e a percepção a respeito desse serviço após ele ter sido prestado. Este último é o mais importante, pois retrata exatamente a discrepância entre a expectativa e a satisfação do cliente, o que não foi considerado (XAVIER, 2010, p. 189).

O modelo SERVPERF foi criado por Cronin e Taylor e tem como objetivo mensurar a percepção e a satisfação do cliente com relação ao desempenho dos serviços prestados (SALOMI; MIGUEL; ABACKERLI, 2005). Tendo como premissa que a qualidade está relacionada à satisfação do cliente e como este vê o desempenho da empresa, o método SERVPERF trouxe benefícios para o âmbito organizacional, proporcionando, além das intenções de recompra, que as empresas obtivessem feedback sobre a qualidade percebida pelos clientes em relação aos serviços oferecidos (GRÖNROOS, 1984 apud AQUINO; JERÔNIMO; MELO, 2015).

A escala SERVPERF é muito utilizada por apresentar um caráter mais prático, referente ao modo de explicar e quantificar a qualidade da prestação de serviço percebida pelos consumidores, levando em consideração todo o processo produtivo para o atendimento do cliente, assim, respeitando as premissas da qualidade total e não somente por meio dos resultados obtidos (AQUINO; JERÔNIMO; MELO, 2015).

É possível mensurar, de acordo com o modelo SERVPERF, a qualidade dos serviços em cinco dimensões, que são: (1) confiabilidade, (2) sensibilidade ou presteza, (3) 


\section{PAVONI; CARDOSO}

segurança, (4) empatia e (5) tangibilidade.

A confiabilidade representa se a empresa cumpre o que foi dito no prazo determinado. A sensibilidade ou presteza representa o quanto os funcionários demonstram disposição em fazer um bom atendimento. A segurança diz respeito à competência que o funcionário tem para executar um determinado serviço. A empatia demonstra se a empresa fornece atenção cuidadosa ao cliente. Por último, a tangibilidade está ligada às instalações físicas e equipamentos. (AQUINO; JERÔNIMO; MELO, 2015, p. 125).

Mondo e Fiates (2015), a partir da análise das publicações brasileiras em revistas Qualis/Capes, estratos A1, A2 e B1 até 2012, localizaram 43 artigos acerca do tema qualidade em serviços, diversos deles com pesquisas empíricas que buscavam mensurar satisfação do cliente e qualidade de serviços e utilizando o modelo SERVPERF.

Alguns estudos, por exemplo, Domingos e Gouvêa (2012), Oliveira, Petry e Borges (2017) e Spina, Giraldi e Oliveira (2013), utilizaram o modelo SERVPERF para identificar a qualidade de serviços em diferentes organizações, tais como hotéis, hospitais, restaurantes, rodoviária, banco, universidade, supermercados. Deve-se ressaltar que os pesquisadores devem adequar o modelo SERVPERF à realidade de suas pesquisas, principalmente ao perfil dos clientes, que podem ser pessoa física, jurídica e ainda de diversos setores.

O Quadro 1 apresenta os modelos e métodos que foram apresentados anteriormente e os principais autores citados que também contribuíram para esta pesquisa. Os procedimentos metodológicos são apresentados a seguir.

Quadro 1 - Quadro síntese dos modelos e métodos de mensuração da satisfação de clientes 
PAVONI; CARDOSO

\begin{tabular}{|c|c|c|}
\hline AUTORES & MODELOS E MÉTODOS & AUTORES CITADOS \\
\hline Xavier (2010) & GAP's & Parasuraman et al. (1985, 1991) \\
\hline Silva e Gonçalves (2007) & ACSI & Hair et al. (2005) \\
\hline Alves et al. (2016) & Kaiser & $\begin{array}{c}\text { Rrtra (2012); Oliver (1999); Abmapro } \\
\text { (2015) }\end{array}$ \\
\hline $\begin{array}{c}\text { Aquino, Jerônimo e Melo } \\
\text { (2015) }\end{array}$ & SERVPERF & Paladini (2012); Grönroos (1984) \\
\hline $\begin{array}{c}\text { Moura Junior et al. (2008) } \\
\text { Relacionamento }\end{array}$ & Vavra (1993) \\
\hline $\begin{array}{c}\text { Giacobo, Estrada e Ceretta } \\
\text { (2003) }\end{array}$ & Logística Reversa \\
\hline $\begin{array}{c}\text { Freire, Crisóstomo e Botelho } \\
\text { (2003) }\end{array}$ & BPAC & Gotler (2000); Lovelace et al. (2001); \\
\hline $\begin{array}{c}\text { Rossi e Slongo (1998) } \\
\text { Adams e Robert (1993) }\end{array}$ & ACSI & $\begin{array}{c}\text { Cronin Jr. e Taylor (1992); Teas } \\
\text { (1993, 1994) }\end{array}$ \\
\hline $\begin{array}{c}\text { Melo, Jerônimo e Aquino } \\
\text { (2016) }\end{array}$ & AHP, QFD e SERVPERF & Embratur (2010); Akao (1990) \\
\hline
\end{tabular}

Fonte: elaborado pelos autores (2018).

\section{PROCEDIMENTOS METODOLÓGICOS}

A empresa foi escolhida por questão de acessibilidade aos seus clientes. Trata-se da empresa Beleza e Arte, que é de pequeno porte, e foi fundada em 2009 no município de Rondonópolis (MT) e, atualmente, atende cerca de 60 clientes por mês com um quadro de três funcionários esteticistas e uma secretária.

Trata-se de um estudo de caso que, conforme Gil (2010), é um meio de se explorar o objeto de estudo de maneira detalhada e complexa. A pesquisa foi realizada por meio de método misto (qualitativo-quantitativo-qualitativo), de modo a obter uma compreensão e explicação mais ampla do tema estudado.

Primeiramente, com base no método SERVPERF, o questionário foi adaptado de Parasuraman et al. (1994 apud GOUVÊA; MASANO; MANTOVANI, 2017, p. 64), conforme o perfil de clientes de uma clínica de estética, utilizando-se de uma escala de 0 a 10, baseando-se nas 5 (cinco) dimensões: confiabilidade, presteza, segurança, empatia e tangibilidade. Assim, às 22 questões foram incluídas 7 (sete) questões sobre os aspectos demográficos dos respondentes e 4 (quatro) questões abertas.

O questionário passou por um teste piloto e, após ligeiros ajustes, foi iniciada a coleta de dados com alguns clientes no início do mês de maio de 2018. Um dos pesquisadores 


\section{PAVONI; CARDOSO}

entregava aos clientes e pedia que preenchessem o questionário, depositando ao final em uma caixa lacrada para não haver identificação das respostas individuais. Após a primeira semana de coleta dos dados, foi realizada a conferência das respostas com a confirmação de que os clientes não encontraram dificuldades em preencher o instrumento. Diante disso, o instrumento foi criado no GoogleForms e enviado por $e$ mail e Whatsapp, além da coleta de respostas presencialmente ter continuado. Após um mês do início da pesquisa, a coleta de dados foi encerrada e os dados tabulados, totalizando 147 respostas válidas ou cerca de $30 \%$ do total de clientes cadastrados.

Quanto ao processo de análise dos dados, além da análise qualitativa das primeiras respostas (preenchimento presencial na $1^{\mathrm{a}}$ semana da pesquisa), foi realizada uma análise quantitativa por meio da estatística descritiva e inferencial, utilizando-se de análise fatorial, testes de confiabilidade, correlações e comparativo entre medidas, que são técnicas multivariadas (FIELD, 2009).

No tratamento dos dados, realizou-se a análise fatorial, correlações e o comparativo entre médias, com testes não paramétricos. Na visão de Field (2009), o propósito da análise de fatores é reduzir um grande conjunto de dados em um subconjunto menor de variáveis; os escores dos fatores representam um escore individual nesse subconjunto de medidas, portanto, qualquer análise adicional pode ser realizada a partir dos fatores em vez de usar todos os dados originais.

Optou-se pelo coeficiente Alfa de Cronbach, para testar a confiabilidade de escala do instrumento, com valor ideal mínimo de 0,7 , podendo ser aceito 0,6 para esta pesquisa exploratória. O coeficiente Alfa de Cronbach $(\alpha)$ é uma medida comumente utilizada de confiabilidade, ou seja, a avaliação da consistência interna dos questionários, para um conjunto de dois ou mais indicadores do constructo. Os valores de $\alpha$ variam de 0 a 1,0; quanto mais próximo de 1, maior a confiabilidade entre os indicadores.

Desta forma, amparado por Field (2009), o uso da análise fatorial busca agrupar variáveis relacionadas a um mesmo constructo (variável latente), propiciando entender a estrutura do conjunto destas variáveis, reduzindo o conjunto dos dados a um tamanho mais manejável (fatores); ademais, indica o autor que, a partir de definição dos fatores, pode-se analisar cada fator, individualmente, a partir dos testes estatísticos usando os comparativos entre médias. Como os testes de normalidade da distribuição e de homogeneidade da variância indicaram valor de SIG superior a 0,05, foram utilizados testes não paramétricos nos comparativos entre as médias, conforme indicado por Field

Revista Eletrônica Gestão e Serviços v.10, n. 1, pp. 2703 - 2730, Janeiro/Junho 2019. ISSN Online: 2177-7284 e-mail: regs@metodista.br 


\section{PAVONI; CARDOSO}

(2009).

As análises tiveram como objetivo testar as seguintes hipóteses:

H1) Há diferenças estatisticamente significativas em relação à satisfação dos clientes considerando que o mesmo respondeu ao questionário dentro ou fora da empresa;

H2) Há diferenças estatisticamente significativas em relação à satisfação dos clientes considerando sua idade;

H3) Há diferenças estatisticamente significativas em relação à satisfação dos clientes considerando o gênero;

H4) Há diferenças estatisticamente significativas em relação à satisfação dos clientes considerando a frequência com que o mesmo realiza procedimentos na empresa;

H5) Há diferenças estatisticamente significativas em relação à satisfação dos clientes considerando sua renda familiar mensal;

H6) Há diferenças estatisticamente significativas em relação à satisfação dos clientes considerando seu grau de escolaridade.

Por fim, uma nova análise qualitativa foi realizada, aplicando-se o processo de codificação (Nuvem de palavras) e categorização (BARDIN, 2009), para evidenciar as descobertas da pesquisa. A Figura 1 representa os procedimentos metodológicos utilizados para a produção da pesquisa.

Figura 1 - Desenho metodológico da pesquisa

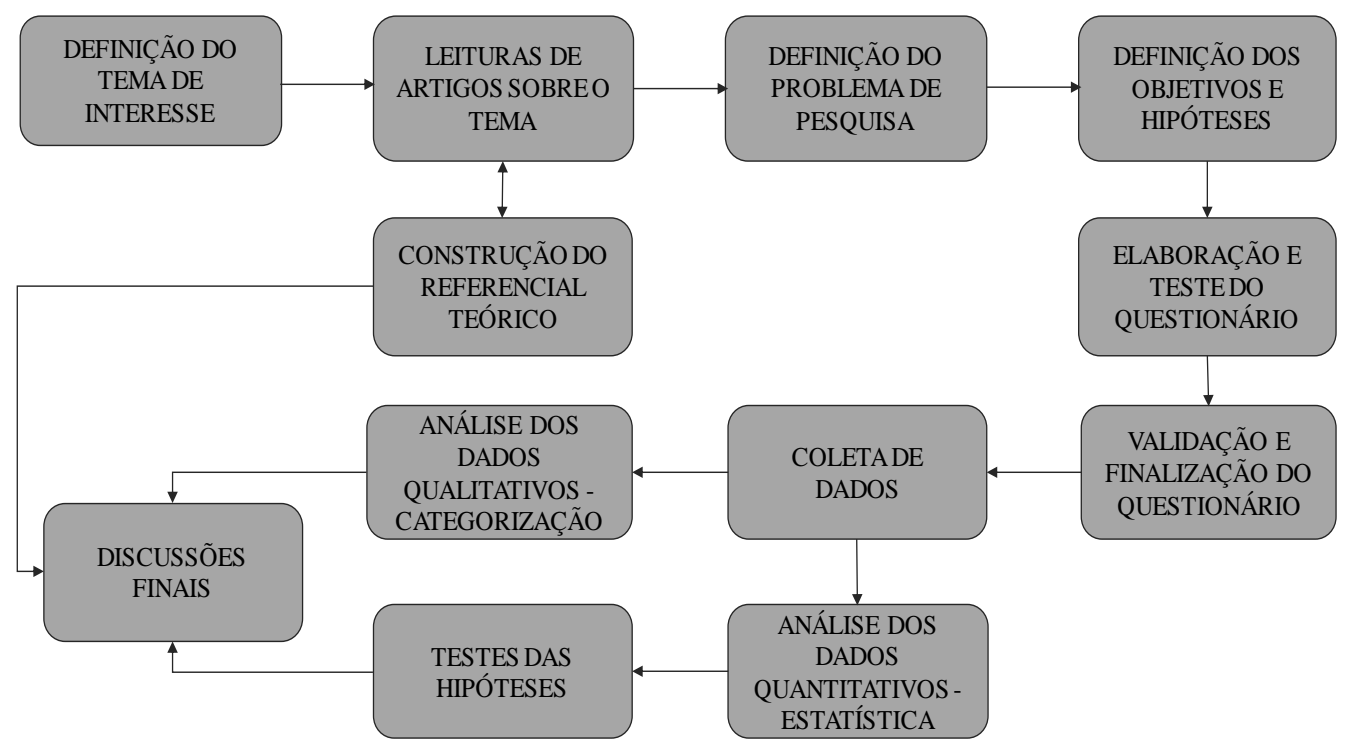

Fonte: elaborado pelos autores (2018).

Revista Eletrônica Gestão e Serviços v.10, n. 1, pp. 2703 - 2730, Janeiro/Junho 2019. ISSN Online: 2177-7284 e-mail: regs@metodista.br 


\section{PAVONI; CARDOSO}

No próximo tópico, são apresentados os dados e discutidos os resultados.

\section{APRESENTAÇÃO DOS DADOS E DISCUSSÃO DOS RESULTADOS}

De todos os 147 respondentes, 122 eram mulheres e 25 homens, com idade média de 32 anos. Os respondentes do questionário físico totalizaram 64, já os respondentes do questionário online totalizaram 83. Em relação à frequência, 59 destes respondentes estavam frequentando a empresa pela primeira vez, 36 já teriam ido algumas vezes e 28 eram clientes frequentes. Com relação à renda, 18 respondentes deixaram em branco, 45 estavam entre 1 e 2 salários mínimos, 63 entre 3 e 5 salários mínimos e apenas 22 com 6 ou mais salários mínimos. Na variável escolaridade, a maioria dos respondentes tinha graduação completa, totalizando 68. Considerando a grande abrangência dos resultados, as variáveis demográficas profissão e bairro não foram utilizadas.

Após o término da coleta de dados, utilizou-se de métodos estatísticos por meio do software SPSS para realizar as análises quantitativas. A estatística descritiva indica elevados valores para as dimensões do modelo SERVPERF, sendo confiabilidade com média 9,2 e desvio-padrão de 0,4; presteza com média de 9,3 e desvio-padrão de 0,2; segurança com média 9,5 e desvio-padrão de 0,1; empatia com média 9,3 e desviopadrão de 0,1; e tangibilidade com média 9,5 e desvio-padrão de 0,1.

Apesar de os resultados indicarem um elevado nível de satisfação, o interesse desta pesquisa foi descobrir as diferenças de percepções dos clientes considerando as variáveis demográficas e identificar possíveis particularidades. Assim, os primeiros testes realizados foram para verificar se os dados eram normalmente distribuídos e se havia homogeneidade da variância. Para o teste de normalidade, deve-se avaliar o valor da significância (SIG), pois para resultados com SIG > 0,05, indica haver normalidade entre os dados e para resultados com $\mathrm{SIG}<0,05$, indica não haver normalidade entre os dados. Para o teste de homogeneidade da variância, com base na média, tem-se a mesma regra: com SIG > 0,05, há homogeneidade da variância dos dados, mas com o SIG < 0,05 , não há homogeneidade da variância dos dados.

Os resultados das análises dos dados revelaram que o teste de normalidade (Kolmogorov-Smirnov) apresentou SIG $<0,05$, indicando não haver normalidade na distribuição dos dados. O teste de homogeneidade (Levene) revelou que nem todas as respostas apresentaram homogeneidade da variância. Desta forma, devem ser utilizados testes não paramétricos.

Revista Eletrônica Gestão e Serviços v.10, n. 1, pp. 2703 - 2730, Janeiro/Junho 2019. ISSN Online: 2177-7284 e-mail: regs@metodista.br 


\section{PAVONI; CARDOSO}

O próximo passo foi rodar a análise fatorial dos dados considerando todas as 22 questões da ferramenta adaptada do modelo SERVPERF. A análise fatorial agrupou em apenas quatro fatores principais que juntos explicaram $67,7 \%$ da variância total dos dados e apresentaram valor de adequação da amostragem, medida Kaiser-Meyer-Olkin (KMO), de 0,915. Este resultado indica que a análise fatorial é uma técnica apropriada para a análise destes dados, considerando que quanto mais próximo de 1, melhor é a adequação da amostragem. Além disso, 67,7\% é um valor considerado razoável na explicação da variância dos dados (FIELD, 2009).

Na visão de Field (2009), o propósito da análise de fatores é reduzir um grande conjunto de dados em um subconjunto menor de variáveis; os escores dos fatores darão um escore individual nesse subconjunto de medidas. "Portanto, qualquer análise adicional pode ser realizada nos escores dos fatores em vez de nos dados originais" (FIELD, 2009, p. 561).

Assim, é possível dizer que os dados estão correlacionados significativamente e que a análise fatorial com redução de fatores é adequada para tratamento subsequente dos dados. A Tabela 1 apresenta o resultado da análise fatorial com as 22 perguntas e sua variância total explicada.

Tabela 1 - Fatores e a variância total explicada sem e com rotação

\begin{tabular}{|c|c|c|c|c|c|c|c|c|c|}
\hline \multirow{2}{*}{ Fatores } & \multicolumn{3}{|c|}{ Autovalores iniciais } & \multicolumn{3}{c|}{$\begin{array}{c}\text { Soma de Extração de } \\
\text { Cargas Quadradas }\end{array}$} & \multicolumn{3}{|c|}{$\begin{array}{c}\text { Soma de Rotação de } \\
\text { Cargas Quadradas }\end{array}$} \\
\cline { 2 - 10 } & Total & $\begin{array}{c}\% \text { de } \\
\text { variância }\end{array}$ & $\begin{array}{c}\% \text { de } \\
\text { variância } \\
\text { acumulada }\end{array}$ & Total & $\begin{array}{c}\% \text { de } \\
\text { variância }\end{array}$ & $\begin{array}{c}\% \text { de } \\
\text { variância } \\
\text { acumulada }\end{array}$ & $\begin{array}{c}\% \text { de } \\
\text { Total }\end{array}$ & $\begin{array}{c}\% \text { de } \\
\text { variância }\end{array}$ \\
acumulada \\
\hline 1 & 10,81 & 49,132 & 49,132 & 10,81 & 49,132 & 49,132 & 5,45 & 24,768 & 24,768 \\
\hline 2 & 1,912 & 8,689 & 57,821 & 1,912 & 8,689 & 57,821 & 4,1 & 18,638 & 43,406 \\
\hline 3 & 1,103 & 5,012 & 62,833 & 1,103 & 5,012 & 62,833 & 2,79 & 12,672 & 56,078 \\
\hline 4 & 1,061 & 4,82 & 67,654 & 1,061 & 4,82 & 67,654 & 2,55 & 11,576 & 67,654 \\
\hline
\end{tabular}

Fonte: dados da pesquisa.

Os fatores encontrados foram nomeados de acordo com os seus atributos de forma lógica e para facilitar a compreensão (RAMPAZZO; RABONI; MELLO, 2018). Assim, tem-se: presteza e segurança, empatia, tangibilidade e confiabilidade. Cabe ressaltar que estes novos fatores foram formados por uma redistribuição das assertivas das dimensões originais da ferramenta adaptada SERVPERF; contudo essa redistribuição será testada em termos de confiabilidade estatística. Cabe ressaltar que este procedimento de 


\section{PAVONI; CARDOSO}

redistribuir as questões em fatores, nomeando-os após a recomposição, também foi feito por estudos anteriores (DOMINGOS; GOUVÊA, 2012; OLIVEIRA; PETRY; BORGES, 2017; SPINA; GIRALDI; OLIVEIRA, 2013) e visa uma discussão a partir da redução dos dados em menos fatores que, juntos, explicam a maior parte da variância dos dados. Um cuidado inicial para aplicar a técnica diz respeito ao tamanho da amostra, pois, assim como no estudo de Domingos e Gouvêa (2012), o mínimo aceitável é que a amostra apresente cinco casos para cada questão. Assim, para as 22 questões em escala Likert de 11 pontos, eram necessárias 110 respostas, o que atende a premissa, pois este número é menor do que as 147 obtidas nesta pesquisa.

O próximo passo foi rodar o teste de confiabilidade aplicado às assertivas de cada fator. Valores maiores que 0,7 são aceitáveis (FIELD, 2009); entretanto, quanto mais próximo de 1 for o resultado do Alpha de Cronbach, maior a confiabilidade da pesquisa. A Tabela 2 apresenta a redução dos dados das 22 perguntas em quatro fatores e seus respectivos valores da estatística descritiva e do Alfa de Cronbach. Tomou-se a decisão por tentar manter os mesmos nomes das dimensões do modelo SERVPERF, mesmo que com algumas ligeiras alterações de agrupamento de assertivas e a consolidação das dimensões presteza e segurança em apenas um fator.

Após o teste de confiabilidade, as cargas dos fatores foram salvas no SPSS para que os testes subsequentes pudessem ser realizados. Assim, além de analisar as correlações entre as variáveis demográficas entre si e os fatores, foram também iniciados os comparativos entre médias, usando o teste de Mann-Whitney (2 variáveis) e o teste de Kruskal-Walis ( $\mathrm{k}>2$ variáveis), para verificar as hipóteses da pesquisa, atender aos objetivos específicos e responder ao problema de pesquisa deste estudo.

As correlações revelam que houve correlação estatisticamente significativa de $+0,214$ envolvendo a variável dentro e fora e o fator empatia. Clientes que preencheram os formulários fora da empresa se mostraram ligeiramente mais satisfeitos quanto ao fator empatia. Houve correlação estatisticamente significativa de $-0,340$ envolvendo a variável idade e o fator empatia. Clientes mais jovens se mostraram levemente mais satisfeitos quanto ao fator empatia. Cabe informar que a maioria dos respondentes do questionário online era de jovens com idade média de 30 anos; já a média dos respondentes do formulário em papel foi de 35 anos. Além disso, houve correlação estatisticamente significativa de $+0,374$ envolvendo a variável renda e o fator empatia. Clientes com maiores rendas se mostraram levemente mais satisfeitos quanto ao fator 


\section{PAVONI; CARDOSO}

empatia. Finalmente, houve correlação estatisticamente significativa de $-0,177$ envolvendo a variável escolaridade e o fator presteza e segurança. Clientes com menor escolaridade se mostraram levemente mais satisfeitos quanto ao fator empatia. Importante salientar que não houve nenhuma correlação estatisticamente significativa envolvendo as variáveis demográficas gênero e frequência.

Nos testes não paramétricos, como Mann-Whitney e Kruskal-Walis, os valores de SIG obedecem a critérios de análise diferentes, sendo SIG $<0,05$, indicando que há significância estatística, e SIG > 0,05, quando não há significância estatística.

\section{Tabela 2 - Fatores, suas assertivas, estatística descritiva e a confiabilidade (Alfa de} Cronbach)

\begin{tabular}{|c|c|c|c|c|c|}
\hline Fatores & Assertivas & Média & Mediana & D.P. & Alfa de Cronbach \\
\hline \multirow{8}{*}{$\begin{array}{l}\text { Presteza e } \\
\text { Segurança }\end{array}$} & Preocupa-se com a satisfação e bem-estar da (o) cliente & 9,5 & 10,0 & 0,8 & \multirow{8}{*}{0.922} \\
\hline & Funcionários estão sempre dispostos para atender a (o) cliente* & 9,5 & 10,0 & 0,7 & \\
\hline & Tem instalações físicas atraentes & 9,7 & 10,0 & 0,6 & \\
\hline & Demonstra habilidade e interesse em lidar com problemas dos clientes* & 9,5 & 10,0 & 0,8 & \\
\hline & Demonstra disposição em auxiliar aos clientes* & 9,5 & 10,0 & 0,8 & \\
\hline & Faz o cliente se sentir seguro em suas transações* & 9,6 & 10,0 & 0,7 & \\
\hline & Funcionários são preparados para responder aos questionamentos* & 9,5 & 10,0 & 0,8 & \\
\hline & Possui funcionários que inspiram confiança* & 9,5 & 10,0 & 0,8 & \\
\hline \multirow{6}{*}{ Empatia } & Possui atendimento individual para as (os) clientes & 9,3 & 10,0 & 0,9 & \multirow{6}{*}{0,857} \\
\hline & Funcionários oferecem atenção personalizada & 9,2 & 9,0 & 0,9 & \\
\hline & Possui funcionários que entendem as necessidades específicas de clientes* & 9,3 & 10,0 & 0,8 & \\
\hline & Possui horário de atendimento conveniente a todos os consumidores* & 9,1 & 9,0 & 1,0 & \\
\hline & Funcionários são consistentemente cordiais* & 9,2 & 9,0 & 0,8 & \\
\hline & Tem agilidade em responder às demandas dos clientes* & 9,0 & 9,0 & 1,1 & \\
\hline \multirow{4}{*}{ Tangibilidade } & Os materiais de comunicação são visualmente atraentes* & 9,3 & 10,0 & 0,9 & \multirow{4}{*}{0,831} \\
\hline & Os funcionários têm boa aparência & 9,6 & 10,0 & 0,6 & \\
\hline & Possui equipamentos modernos e de qualidade* & 9,5 & 10,0 & 0,7 & \\
\hline & Os profissionais se preocupam com a (o) cliente mesmo no pós-serviço* & 9,4 & 10,0 & 0,8 & \\
\hline \multirow{4}{*}{ Confiabilidade } & Não comete erros & 8,7 & 9,0 & $\overline{1,6}$ & \multirow{4}{*}{0,703} \\
\hline & Oferece o serviço correto já na primeira vez & 9,2 & 10,0 & 1,2 & \\
\hline & Oferece os serviços conforme prometido & 9,3 & 10,0 & 1,0 & \\
\hline & Oferece o serviço no prazo prometido* & 9,6 & 10,0 & 0,7 & \\
\hline
\end{tabular}

Fonte: dados da pesquisa. Nota. DP é o desvio padrão da amostra; * indica assertivas adaptadas para esta pesquisa

Utilizou-se do comparativo entre médias não paramétrico, conhecido como MannWhitney para encontrar correlações específicas para variáveis com duas posições (ex. gênero), o teste não paramétrico de Kruskal-Wallis para variáveis com mais de duas 


\section{PAVONI; CARDOSO}

posições (ex. renda). A seguir, são apresentados os testes de hipóteses.

H1) Há diferenças estatisticamente significativas em relação à satisfação dos clientes considerando que o mesmo respondeu ao questionário dentro ou fora da empresa.

Considerando o exposto por Field (2009), a partir da descoberta dos fatores, reduzindo o conjunto de dados em um subconjunto menor de variáveis, cada fator representa um escore individual nesse subconjunto de medidas, portanto, qualquer análise adicional pode ser realizada a partir dos fatores em vez de usar todos os dados originais. Neste caso, conforme dados da Tabela 3, a hipótese 1 (H1) foi corroborada, pois há diferenças de percepção sobre a empatia na visão dos clientes que responderam à pesquisa dentro do espaço físico ou via internet. Pode-se salientar que mesmo os demais fatores não apresentando diferenças estatisticamente significativas, basta um dos fatores indicar diferença para corroborar a hipótese aqui especificada.

Tabela 3 - Comparações entre respondentes dentro ou fora - Teste Mann-Whitney

\begin{tabular}{|c|c|c|c|c|}
\hline \multirow{2}{*}{ Mann-Whitney U } & $\begin{array}{c}\text { Presteza e } \\
\text { Segurança }\end{array}$ & Empatia & Tangibilidade & Confiabilidade \\
\cline { 2 - 5 } & 1857,5 & 1516,5 & 1731,5 & 1816,5 \\
\hline Wilcoxon W & 3082,5 & 2741,5 & 5217,5 & 5302,5 \\
\hline Z & $-0,833$ & $-2,446$ & $-1,429$ & $-1,027$ \\
\hline Sig. (2-tailed) & 0,405 & 0,014 & 0,153 & 0,305 \\
\hline
\end{tabular}

Fonte: dados da pesquisa.

H2) Há diferenças estatisticamente significativas em relação à satisfação dos clientes considerando sua idade.

A mesma análise pode ser empregada para a verificação de diferenças conforme a idade. Sendo assim, a hipótese $2(\mathrm{H} 2)$ foi corroborada, pois há diferença estatisticamente significativa envolvendo o fator empatia e a variável idade, conforme Tabela 4.

Tabela 4 - Variável idade - Teste Kruskal-Wallis

\begin{tabular}{|c|c|c|c|c|}
\hline Kruskal-Wallis & $\begin{array}{c}\text { Presteza e } \\
\text { Segurança }\end{array}$ & Empatia & Tangibilidade & Confiabilidade \\
\hline Chi-Square & 0,021 & 14,817 & 2,885 & 0,449 \\
\hline Df & 2 & 2 & 2 & 2 \\
\hline Asymp. Sig. & 0,989 & 0,001 & 0,236 & 0,799 \\
\hline
\end{tabular}

Fonte: dados da pesquisa.

Foi realizado, também, para a variável idade, o teste Mann-Whitney separando os blocos 1 (15 a 30 anos), 2 (31 a 45 anos) e 3 (46 a 60 anos), a fim de encontrar qual destes

Revista Eletrônica Gestão e Serviços v.10, n. 1, pp. 2703 - 2730, Janeiro/Junho 2019.

ISSN Online: 2177-7284 e-mail: regs@ metodista.br 


\section{PAVONI; CARDOSO}

apresentaria diferenças estatisticamente significativas. Apenas a relação dos blocos 2 e 3 não apresentou diferenças estatisticamente significativas. Os blocos 1 e 2 e 1 e 3 apresentaram diferenças estatisticamente significativas com o fator empatia, conforme Tabela 5.

Tabela 5 - Comparações entre respondentes das diferentes idades - Teste MannWhitney

\begin{tabular}{|c|c|c|c|c|c|}
\hline Fator & Blocos de Idade & \# & Média do Rank & SIG. & Resultado \\
\hline \multirow{6}{*}{ Empatia } & 15 a 30 anos & 65 & 72,78 & \multirow{2}{*}{0,000} & \multirow{2}{*}{ Há Diferenças } \\
\hline & 31 a 45 anos & 58 & 49,92 & & \\
\hline & 15 a 30 anos & 65 & 37,58 & \multirow{2}{*}{0,033} & \multirow{2}{*}{ Há Diferenças } \\
\hline & 46 a 60 anos & 6 & 18,92 & & \\
\hline & 31 a 45 anos & 58 & 32,98 & \multirow{2}{*}{0,518} & \multirow{2}{*}{ Não Há Diferenças } \\
\hline & 46 a 60 anos & 6 & 27,83 & & \\
\hline
\end{tabular}

Fonte: dados da pesquisa. Nota: nem todos os respondentes informaram sua idade.

H3) Há diferenças estatisticamente significativas em relação à satisfação dos clientes considerando o gênero.

Hipótese 3 (H3) não foi corroborada. Não há diferenças de percepção significativas entre o gênero em relação aos fatores, conforme Tabela 6.

Tabela 6 - Comparações entre os gêneros masculino e feminino - Teste Mann-Whitney

\begin{tabular}{|c|c|c|c|c|}
\hline \multirow{2}{*}{ Mann-Whitney U } & $\begin{array}{c}\text { Presteza e } \\
\text { Segurança }\end{array}$ & Empatia & Tangibilidade & Confiabilidade \\
\cline { 2 - 5 } & 1109 & 1255 & 1125 & 1004 \\
\hline Wilcoxon W & 1409 & 1555 & 1425 & 6890 \\
\hline Z & $-1,108$ & $-0,243$ & $-1,013$ & $-1,73$ \\
\hline Sig. (2-tailed) & 0,268 & 0,808 & 0,311 & 0,084 \\
\hline
\end{tabular}

Fonte: dados da pesquisa.

H4) Há diferenças estatisticamente significativas em relação à satisfação dos clientes considerando a frequência com que o mesmo realiza procedimentos na empresa.

A hipótese 4 (H4) não foi corroborada. Não há diferenças estatisticamente significativas entre as variáveis frequência e os fatores, conforme Tabela 7.

Tabela 7 - Variável frequência e sua relação com os fatores - Teste Kruskal-Wallis

\begin{tabular}{|c|c|c|c|c|}
\hline Kruskal-Wallis & $\begin{array}{c}\text { Presteza e } \\
\text { Segurança }\end{array}$ & Empatia & Tangibilidade & Confiabilidade \\
\hline Chi-Square & 1,609 & 1,51 & 1,395 & 2,697 \\
\hline Df & 2 & 2 & 2 & 2 \\
\hline Asymp. Sig. & 0,447 & 0,470 & 0,498 & 0,260 \\
\hline
\end{tabular}

Fonte: dados da pesquisa.

Revista Eletrônica Gestão e Serviços v.10, n. 1, pp. 2703 - 2730, Janeiro/Junho 2019.

ISSN Online: 2177-7284 e-mail: regs@metodista.br 
H5) Há diferenças estatisticamente significativas em relação à satisfação dos clientes considerando sua renda familiar mensal.

Devido à grande discrepância das respostas na variável renda, foi necessário dividi-la em três grupos: de 1 a 2 salários mínimos, de 3 a 5 salários mínimos e de 6 ou mais salários mínimos. Hipótese 5 (H5) foi corroborada. Há diferenças estatisticamente significativas de percepção sobre os níveis de satisfação dos clientes com relação à empatia, considerando a variável renda, conforme Tabela 8.

Tabela 8 - Variável renda e sua relação com os fatores - Teste Kruskal-Wallis

\begin{tabular}{|c|c|c|c|c|}
\hline Kruskal-Wallis & $\begin{array}{c}\text { Presteza e } \\
\text { Segurança }\end{array}$ & Empatia & Tangibilidade & Confiabilidade \\
\hline Chi-Square & 2,293 & 16,24 & 1,12 & 0,805 \\
\hline Df & 2 & 2 & 2 & 2 \\
\hline Asymp. Sig. & 0,318 & 0 & 0,571 & 0,669 \\
\hline
\end{tabular}

Fonte: dados da pesquisa.

Da mesma forma que a variável idade, foram realizados os testes de Mann-Whitney envolvendo os grupos de renda, dois a dois. Assim, indica-se, pela Tabela 9, que há diferenças estatisticamente significativas com respeito ao fator empatia entre os blocos de renda 1 e 2 e 1 e 3 , sendo as menores médias do rank associados às respondentes de renda de 1 a 2 salários mínimos.

Tabela 9 - Comparações entre os grupos de rendas - Teste Mann-Whitney

\begin{tabular}{|c|c|c|c|c|c|}
\hline Fator & Blocos de Renda & \# & Média do Rank & SIG. & Resultado \\
\hline \multirow{6}{*}{ Empatia } & 1 a 2 salários mínimos & 42 & 39,61 & \multirow{2}{*}{0,003} & \multirow{2}{*}{ Há Diferenças } \\
\hline & de 3 a 5 salários mínimos & 56 & 56,92 & & \\
\hline & 1 a 2 salários mínimos & 42 & 25,31 & \multirow{2}{*}{0,000} & \multirow{2}{*}{ Há Diferenças } \\
\hline & de 6 ou mais salários mínimos & 19 & 43,58 & & \\
\hline & de 3 a 5 salários mínimos & 56 & 35,86 & \multirow{2}{*}{0,142} & \multirow{2}{*}{ Não Há Diferenças } \\
\hline & de 6 ou mais salários mínimos & 19 & 44,32 & & \\
\hline
\end{tabular}

Fonte: dados da pesquisa.

H6) Há diferenças estatisticamente significativas em relação à satisfação dos clientes considerando seu grau de escolaridade.

Hipótese 6 (H6) não foi corroborada, pois a análise não identificou diferenças estatisticamente significativas entre a variável escolaridade e os fatores, vide Tabela 10. 
PAVONI; CARDOSO

Tabela 10 - Variável escolaridade e sua relação com os fatores - Teste KruskalWallis

\begin{tabular}{|c|c|c|c|c|}
\hline Kruskal-Wallis & $\begin{array}{c}\text { Presteza e } \\
\text { Segurança }\end{array}$ & Empatia & Tangibilidade & Confiabilidade \\
\hline Chi-Square & 11,763 & 8,364 & 2,327 & 4,119 \\
\hline Df & 6 & 6 & 6 & 6 \\
\hline Asymp. Sig. & 0,067 & 0,213 & 0,887 & 0,661 \\
\hline
\end{tabular}

Fonte: dados da pesquisa.

Entre as seis hipóteses lançadas neste estudo, sobre haver diferenças estatisticamente significativas envolvendo os aspectos demográficos e os fatores descobertos, apenas três foram corroboradas, salientando haver diferenças somente no fator empatia.

Depois das análises quantitativas, foram também trabalhadas as respostas dadas às questões abertas buscando evidenciar as descobertas da análise quantitativa. Num primeiro momento, as respostas das perguntas abertas foram transcritas literalmente, depois recortadas, separadamente, em fragmentos com significados, subcategorias e, por fim, agrupadas, criando as categorias temáticas. Para melhor visualização, foram elaboradas nuvens de palavras no software Tagul (disponível em https://wordart.com) que representassem as palavras com maior ênfase de acordo com cada pergunta qualitativa. Optou-se por gerar uma única imagem, conforme Figura 2.

Os clientes avaliam o atendimento, na maioria das vezes, apenas como bom ou ruim; todavia, de acordo com as respostas dos clientes da empresa Beleza e Arte, para a categoria atendimento, o termo abrange muito mais que isso e, considerando sua importância, o mesmo pode ser facilmente confundido com qualidade, pois os clientes associam qualidade ao atendimento de qualidade. Observa-se que o cliente avaliou o atendimento desde o primeiro contato com a empresa, logo na recepção, dizendo que a empresa "atende todos os públicos"; segundo o respondente $n^{\circ} 53$, "bom trabalho", conforme o respondente $\mathrm{n}^{\mathrm{o}} 85$; “atendimento dos funcionários", de acordo com o respondente $\mathrm{n}^{\mathrm{o}} 133$, entre outros elogios.

A categoria profissionalismo pode ser apresentada considerando: capacitação e qualificação do profissional, comprometimento, pontualidade, assiduidade, dedicação, credibilidade, seriedade, etc. Os clientes dizem valorizar e considerar o profissionalismo como elemento importante na visão de uma clínica de estética ideal e, por fim, dizem estar satisfeitos, por terem escolhido a empresa Beleza e Arte, considerando o profissionalismo. A respondente $\mathrm{n}^{\mathrm{o}} 53 \mathrm{diz}$ que a profissional tem "o cuidado em nos 


\section{PAVONI; CARDOSO}

deixar satisfeita"; a respondente $\mathrm{n}^{\circ} 69$ diz confiar na "competência da profissional"; para o correspondente n 133 , a "profissional é capacitada".

Figura 2 - Desenho elaborado a partir das respostas das perguntas qualitativas

\section{O que você valoriza em uma clínica de estética?}

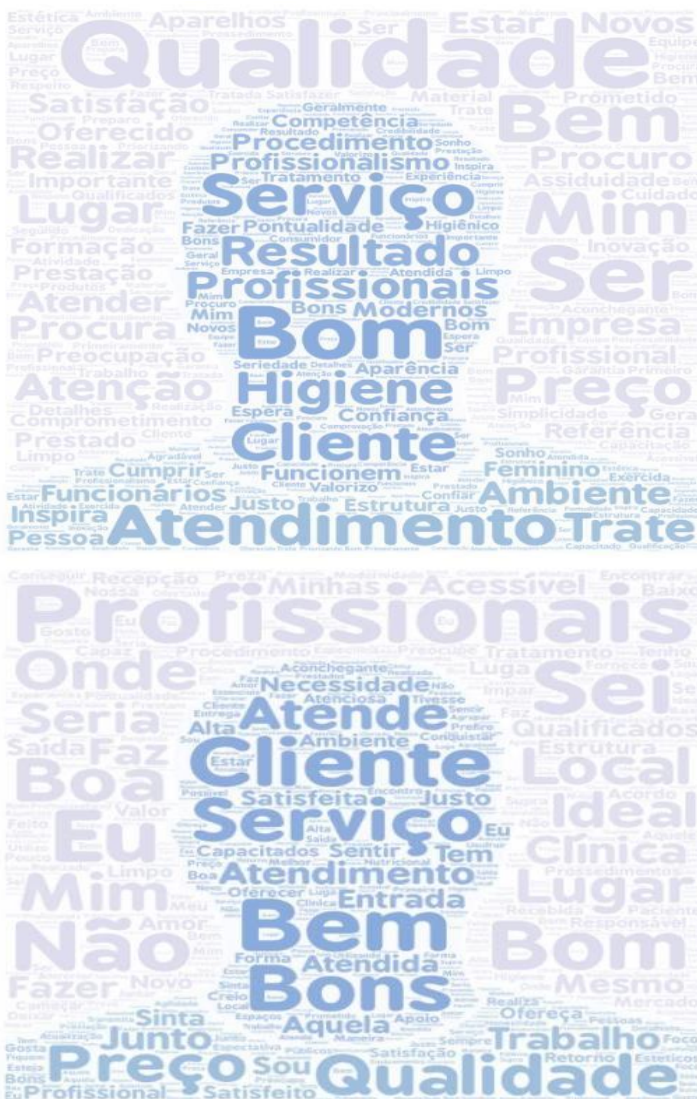

3. Para você o que seria uma clínica de estética ideal?
2. O que você leva em consideração na hora de escolher uma clínica de de estética?
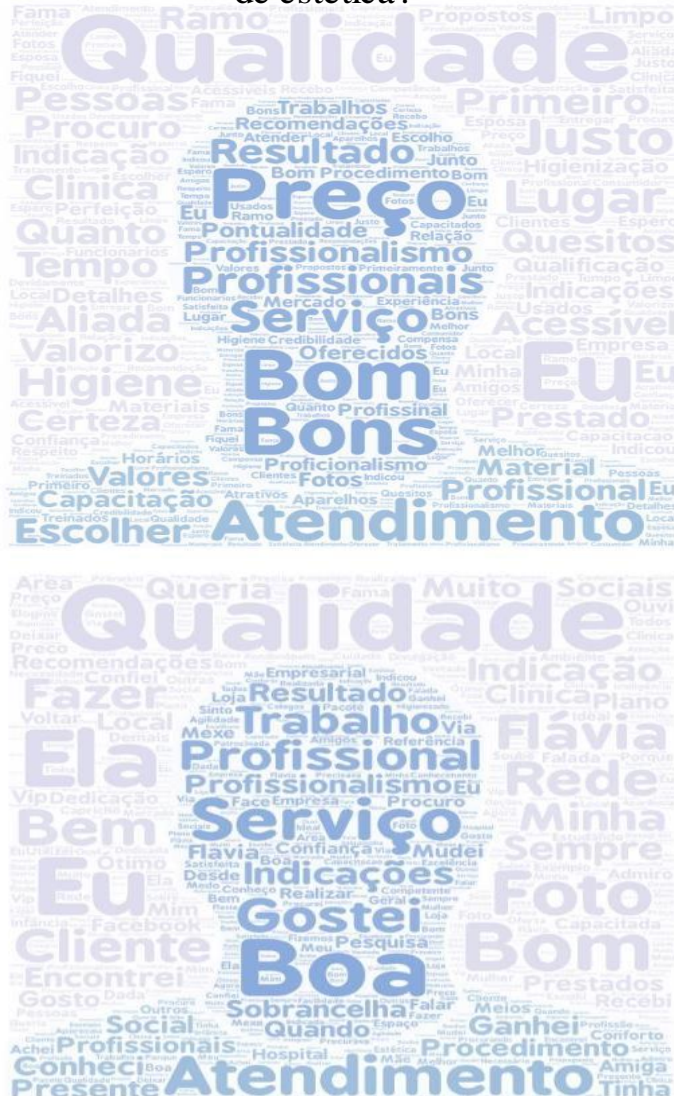

4. O que te levou a escolher nossos serviços?

Fonte: elaborado pelos autores (2018).

Para os clientes, a categoria preço influencia na escolha do local para realizar algum procedimento estético e, estando satisfeito com o preço, a chance de recompra também aumenta. Muitos respondentes indicaram sua satisfação sobre a categoria preço, por exemplo, o respondente $\mathrm{n}^{\circ} 56$ diz que a empresa Beleza e Arte tem "preço acessível" e o respondente $\mathrm{n}^{\mathrm{o}} 79$ complementa dizendo que tem "preço justo".

A categoria comunicação diz respeito ao marketing realizado pela empresa, a mídia, as fotos divulgadas em redes sociais, descontos e promoções. Assim, como muitos clientes, a respondente $\mathrm{n}^{\circ} 93$ afirmou na $4^{\mathrm{a}}$ pergunta que, para ela, "ver as fotos dos serviços prestados" foi um dos motivos pelos quais a mesma escolheu realizar o 


\section{PAVONI; CARDOSO}

procedimento na empresa, e hoje ela se sente satisfeita.

Na categoria espaço físico, pode-se dizer que os clientes prezam por um ambiente higienizado, limpo, agradável, que ofereça conforto, boa estrutura, materiais adequados e os aparelhos modernos, entre outros critérios. É possível dizer então que, se a empresa está dentro destes padrões, o cliente se sente mais satisfeito.

A partir da análise qualitativa dos dados é possível indicar que a categoria satisfação do cliente está ligada com a qualidade percebida na prestação do serviço. Logo na primeira pergunta, o respondente $\mathrm{n}^{\circ} 7 \mathrm{diz}$ que valoriza "qualidade na prestação de serviço". O respondente $\mathrm{n}^{\circ} 9$, na $2^{\mathrm{a}}$ pergunta, leva em consideração a "qualidade do serviço". Na hora de dizer o que seria uma clínica de estética ideal, o respondente $\mathrm{n}^{\circ} 66$ diz que, para ele, é aquela "que faz o serviço bem feito". Já para a $4^{a}$ pergunta, que diz respeito ao motivo pelo qual o cliente escolheu a empresa Beleza e Arte, o respondente n 56 afirmou ser pela "qualidade do serviço". A categoria satisfação do cliente, diante das análises quantitativas e qualitativas, mostrou que os clientes da empresa Beleza e Arte estão satisfeitos. Na medida em que o cliente se sente satisfeito, acontecem as indicações, recomendações e motivação para recompra, o que faz com que a empresa seja valorizada pelo trabalho que faz. Os respondentes afirmaram estar satisfeitos, com respostas como a da respondente $n^{\circ} 141$, "me sinto realizada", ou do respondente $\mathrm{n}^{\circ} 87$ que diz "que o profissional deixa os clientes supersatisfeitos"; ainda conforme a resposta da segunda respondente, indicando que "eu não frequentaria uma abaixo deste nível”.

Estas sete categorias permeiam as cinco dimensões do modelo SERPERF, todas relacionadas a aspectos salientados pelos clientes para indicar o seu nível de satisfação com o serviço prestado, com a empresa e com os funcionários. Assim, relacionando as descobertas desta pesquisa e os conceitos apresentados no referencial teórico, pode-se elencar alguns dos diferentes elementos para discutir os resultados. Por exemplo, destaque para relação entre as expectativas antecedentes e os resultados consequentes em um processo completo de experiência do cliente com o serviço (BOAS et al., 2003; FERNANDES; SANTOS, 2008; GASTAL, 2005; HELENA; SPERS, 2005; JURAN, 1997; KOTLER, 2000), e as demais experiências que podem reforçar o nível de satisfação ou apresentar uma deterioração ao longo do tempo. Os sentimentos e a expressividade que podem ser identificadas na divulgação e comunicação que um cliente faz sobre a empresa (SANTOS; FERNANDES, 2008), após uma relação de 


\section{PAVONI; CARDOSO}

compra ou de recompra, reforça a ideia de satisfação específica e cumulativa (FORNELL; LEHMANN, 1994 apud GASTAL, 2005), além de um elemento de caráter bidimensional (SANTOS; FERNANDES, 2008) que envolve a confiança nos funcionários e a política de atendimento e prestação de serviço da empresa como um todo, podendo se criar um sentimento de valorização (GOUVÊA; MASANO; MANTOVANI, 2017) e, a certo termo, de lealdade e fidelidade com a recompra do serviço (GASTAL, 2005).

Os diversos elementos identificados nas sete categorias e que permeiam os fatores se mostram coerentes com o referencial utilizado neste estudo. Os dados indicam alinhamento, pois tanto a análise quantitativa, pela estatística descritiva, que mostrou altos índices de satisfação nas medidas de média e mediana e baixo desvio padrão, quanto pela análise inferencial que revelou que, mesmo com esses altos índices, havia algumas diferenças estatisticamente significativas, e com isso, reforçam as descobertas. Ademais, a análise qualitativa colabora na composição de especificações mais detalhadas das percepções, indicadas nas respostas abertas (Figura 2). Assim, é possível fazer um desenho dessas categorias identificadas na análise qualitativa associando aos quatro fatores trabalhados na análise quantitativa, conforme Figura 3.

Figura 3 - Desenho das categorias envolvendo as dimensões da satisfação dos clientes de uma pequena empresa do ramo da estética

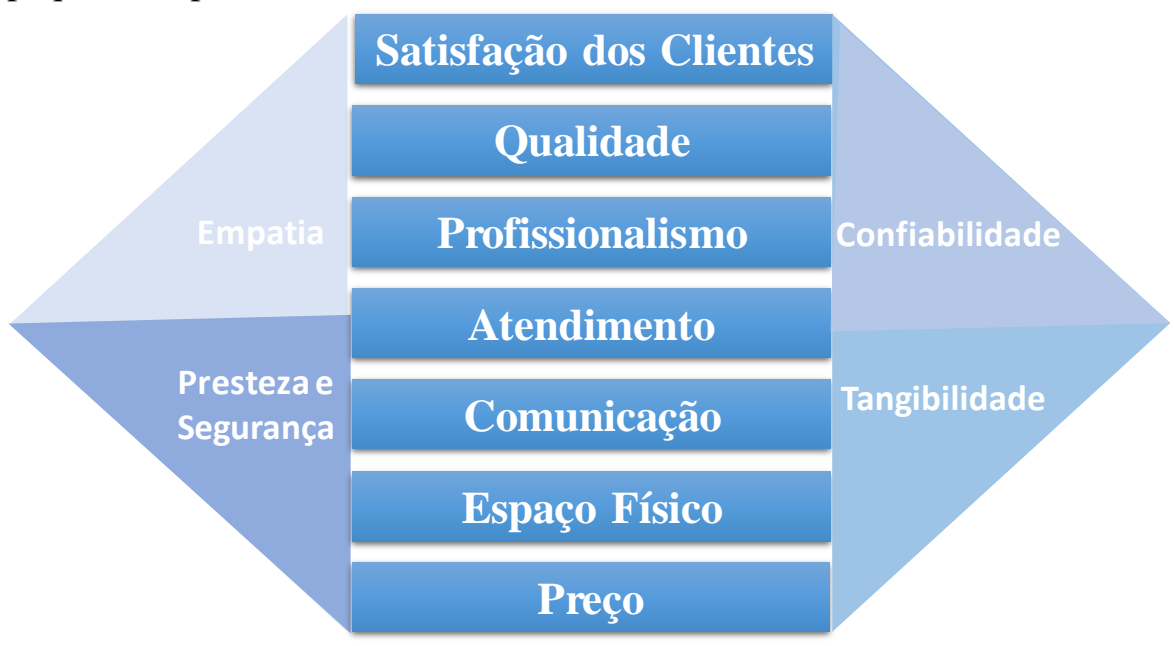

Fonte: elaborado pelos autores (2018).

A partir da Figura 3, é possível indicar que a satisfação do cliente é percebida por um conjunto de elementos formados pelas diversas categorias aqui encontradas, apresentando a satisfação dos clientes. Reforça-se que, de forma integrada, as perguntas da Figura 2 têm suas respostas integradas na Figura 3. 


\section{PAVONI; CARDOSO}

\section{CONSIDERAÇÕES FINAIS}

Este estudo teve como objetivo analisar o nível de satisfação dos clientes em uma empresa de pequeno porte na cidade de Rondonópolis (MT). A empresa escolhida foi a Beleza e Arte, que atua no ramo da estética desde 2009. Trata-se de um estudo de natureza qualitativa e quantitativa, envolvendo 147 respondentes.

Baseando-se na análise fatorial, foram encontrados quatro fatores nomeados: relação cliente-funcionários, atendimento, relação profissionais-espaço físico e serviços. A partir da redistribuição das questões adaptadas do modelo SERVPERF nestes fatores, foi possível dizer que os dados estão correlacionados significativamente e que o instrumento utilizado foi perfeitamente adequado para tratamento dos dados.

Os testes de normalidade e da homogeneidade indicaram não haver normalidade na distribuição dos dados e, como nem todas as respostas apresentaram homogeneidade da variância, foram utilizados testes não paramétricos. A partir do comparativo entre as médias, baseando-se nas hipóteses lançadas nesta pesquisa, três hipóteses foram corroboradas e três não corroboradas. Com uma estrutura hierárquica, a categoria satisfação do cliente, que é o enfoque geral deste estudo, para tanto, encontra-se em destaque entre as sete categorias encontradas na análise qualitativa dos dados e as outras categorias complementam os requisitos avaliados pelos clientes.

A primeira contribuição deste estudo é teórica e metodológica, ampliando o conhecimento científico sobre o assunto, apresentando as diferentes percepções dos clientes sobre a satisfação, de acordo com os aspectos demográficos, além de apresentar um conjunto de assertivas que pode ser empregado em estudos futuros para outras empresas de serviços de pequeno porte. A segunda contribuição é prática, pois este estudo apresenta informações valiosas que podem contribuir com possíveis melhorias dentro da empresa, baseando-se nos resultados encontrados, a fim de satisfazer, atender e manter a expectativa de seus clientes, o que é fundamental na construção de estratégias de tomada de decisão (ROSSI; SLONGO, 1998) com foco em determinados grupos específicos de clientes em seus feedbacks.

\section{REFERÊNCIAS}

ALMEIDA, G. S.; CARNEIRO, T. C. J.; PELISSARI, A. S. Qualidade do serviço e suas consequênicas: uma análise bibliométrica. Revista Eletrônica Gestão e Serviços, São Bernardo do Campo, v. 8, n. 2, p. 1965-1988, 2017. 
ALVES, A. C. et al. A Percepção da Satisfação pelos Clientes de Marcas Próprias. Revista Pensamento Contemporâneo em Administração, Rio de Janeiro, v. 10, n. 4, p. 114-129, 2016.

AQUINO, J. T.; JERÔNIMO, T. B.; MELO, F. J. C. Avaliação da qualidade em serviço de um hotel pelo Método SERVPERF. Revista Pensamento Contemporâneo em Administração, Rio de Janeiro, v. 9, n. 1, p. 124-141, 2015.

BARDIN, L. Análise de conteúdo. Lisboa, Portugal: Edições 70: LDA, 2009.

BATESON, J. E. G.; HOFFMAN, D. Marketing de Serviços. 4. ed. Porto Alegre: Bookman, 2001.

BEULKE, M. G. Pesquisa de satisfação de clientes: um estudo no setor de TV por assinantes no mercado de Porto Alegre. In: ENCONTRO DA ASSOCIAÇÃO NACIONAL DOS PROGRAMAS DE PÓSGRADUAÇÃO EM ADMINISTRAÇÃO, XXII ENANPAD, 1998, Foz do Iguaçu. Anais [...]. Foz do Iguaçu: ENANPAD, 1998.

BOAS, S. F. V. et al. Medição de satisfação do cliente na área de serviços. In: ENCONTRO NACIONAL DE ENGENHARIA DE PRODUÇÃO, XXIII ENEGEP, 2003, Ouro Preto. Anais [...]. Ouro Preto: ENEGEP, 2003.

DOMINGOS, O.; GOUVÊA, M. A. Qualidade de vida percebida em atividades de gerenciamento por categorias em supermercados. REGE - Revista de Gestão, São Paulo, v. 19, n. 4, p. 589-608, 2012.

FARIAS, S. A.; SANTOS, R. C. Modelagem de equações estruturais e satisfação do consumidor: uma investigação teórica e prática. Revista de Administração Contemporânea, Maringá, v. 4, n. 3, p. 107-132, set./dez. 2000.

FERNANDES, D. V. D. H.; SANTOS, C. P. D. As consequências comportamentais da insatisfação dos clientes. Revista de Administração Contemporânea, Maringá, v. 12, n. especial, p. 147-174, 2008.

FIELD, A. Descobrindo a Estatística usando o SPSS. 2. ed. Porto Alegre: Artmed, 2009.

FREIRE, F. S.; CRISÓSTOMO, V. L.; BOTELHO, D. R. Um método quantitativo para avaliação da satisfação dos clientes. Revista Contabilidade \& Finanças - USP, São Paulo, v. 14, n. 31, p. 7-15, 2003.

GASTAL, F. A Influência da satisfação e dos custos de mudança na lealdade do cliente. 2005. 179 f. Dissertação (Mestrado) - Programa de Pós-Graduação em Administração, Escola de Administração, Universidade Federal do Rio Grande do Sul, Porto Alegre, 2005.

GIACOBO, F.; ESTRADA, R.; CERETTA, P. S. Logística reversa: a satisfação do cliente no pós-venda. REAd. Revista Eletrônica de Administração, Porto Alegre, v. 9, n. 5, p. 1-17, 2003.

GIANESI, I. G. N.; CORRÊA, H. L. Administração estratégica de serviços: operações para satisfação do cliente. São Paulo: Atlas, 1994.

GIL, A. C. Métodos e técnicas de pesquisa social. São Paulo: Atlas, 2010.

GOUVÊA, M. A.; MASANO, A. C. R.; MANTOVANI, D. M. N. Avaliação de Serviços Bancários no Segmento de Alta Renda na Cidade de São Paulo. Revista de Administração da UFSM, Santa Maria, v. 10, n. 1, p. 60-84, 2017.

Revista Eletrônica Gestão e Serviços v.10, n. 1, pp. 2703 - 2730, Janeiro/Junho 2019.

ISSN Online: 2177-7284 e-mail: regs@metodista.br 
HELENA, L. A.; SPERS, E. E. Modelos de mensuração da satisfação de clientes: um estudo de caso com alunos de Administração. Revista de Ciências da Administração, Florianópolis, v. 7, n. 13, p. 67-86, 2005.

JURAN, J. M. A Qualidade desde o projeto: novos passos para o planejamento da qualidade em produtos e serviços. 3. ed. São Paulo: Pioneira, 1997.

KOTLER, P. Administração de marketing. 10. ed. São Paulo: Prentice Hall, 2000.

MAGALDI, S.; CRESCITELLI, E. A importância dos serviços suplementares no setor de serviços: uma análise do nível de satisfação do cliente. REGE - Revista de Gestão, São Paulo, v. 15, n. 3, p. 67-75, 2008.

MARCHETTI, R.; PRADO, P. H. M. Um tour pelas medidas de satisfação do consumidor. RAE - Revista de Administração de Empresas, São Paulo, v. 41, n. 4, p. 56-67, 2001.

MELO, F. J. C.; JERÔNIMO, T. B.; AQUINO, J. T. Avaliação Multicriterial da Qualidade em Serviços: um Estudo de Caso em um Hotel. Revista Pensamento Contemporâneo em Administração, Rio de Janeiro, v. 10, n. 3, p. 117-133, 2016.

MONDO, T. S.; FIATES, G. G. S. Mapeamento Bibliométrico dos Modelos de Qualidade em Serviços: Publicações de pesquisadores brasileiros sobre o tema até 2012. Revista Brasileira de Marketing, São Paulo, v. 15, n. 1, p. 11-28, 2015.

OLIVEIRA, A. C.; PETRY, J. F.; BORGES, G. da R. Mensuração da qualidade do comércio de Balsas, MA, por meio da escala RSQ. Revista Eletrônica Gestão e Serviços, São Bernardo do Campo, v. 7, n. 2, p. 1602-1623, 2017.

RAMPAZZO, N. L.; RABONI, P. L.; MELLO, P. R. C. B. de. O significado do trabalho na indústria criativa: um estudo no porto digital do Recife (Brasil). Revista Capital Científico, Guarapuava, v. 16, n. 3, p. 95-108, jul./set. 2018.

RODRIGUES, A. C. de M. Qualidade de serviços e satisfação do consumidor: aspectos conceituais distintivos. In: ENCONTRO DA ASSOCIAÇÃ O NACIONAL DOS PROGRAMAS DE PÓSGRADUAÇÃO EM ADMINISTRAÇÃO, XXIV ENANPAD, 2000. Florianópolis. Anais [...]. Florianópolis: ENANPAD, 2000.

ROSSI, C. A. V.; SLONGO, L. A. Pesquisa de satisfação de clientes: o estado-da-arte e proposição de um método brasileiro. Revista de Administração Contemporânea, Maringá, v. 2, n. 1, p. 101-125, 1998.

SALOMI, G. G. E.; MIGUEL, P. A. C.; ABACKERLI, A. J. SERVQUAL X SERVPERF: Comparação entre instrumentos para avaliação da qualidade de serviços internos. Revista Gestão \& Produção, São Carlos, v. 12, n. 2, p. 279-293, 2005.

SANTOS, C. P. D.; FERNANDES, D. V. D. H. A recuperação de serviços como ferramenta de relacionamento e seu impacto na confiança e lealdade dos clientes. RAE - Revista de Administração de Empresas, São Paulo, v. 48, n. 1, p. 10-24, jan./mar. 2008.

SILVA, E. M.; GONÇALVES, C. A. Correlação entre satisfação do consumidor e desempenho organizacional. Revista Pretexto, Belo Horizonte, v. 8, n. 1, p. 9-24, 2007.

SPINA, D. T.; GIRALDI, J. de M. E.; OLIVEIRA, M. M. B. de. A Influência Das Dimensões Da Qualidade De Serviços Na Satisfação Do Cliente: Um Estudo Em Uma Empresa Do Setor De Controle De Pragas. REGE - Revista de Gestão, São Paulo, v.

Revista Eletrônica Gestão e Serviços v.10, n. 1, pp. 2703 - 2730, Janeiro/Junho 2019. ISSN Online: 2177-7284 e-mail: regs@metodista.br 
20, n. 1, p. 93-112, 2013.

XAVIER, R. N. Avaliação da qualidade dos serviços de uma Instituição de Ensino Superior utilizando a aplicação do modelo adaptado de mensuração dos 5 GAP's. Revista Capital Científico - Eletrônica, Guarapuava, v. 7, n. 1, p. 129-137, 2010.

ZEITHAML, V. A.; BITNER, M. J. Marketing de Serviços: a empresa com foco no cliente. 22. ed. Porto Alegre 